\title{
Precisely Controlling the Output Force of Hydrogel Actuator Based on Thermodynamically Non-Equilibrium Temporary Deformation
}

Jincai Yin ${ }^{\mathrm{a}, 1}$, Delin Zhang ${ }^{\mathrm{a}, 1}$, Zihan Xu ${ }^{\mathrm{a}}$, Wenxin Fana,*, Yanzhi Xia ${ }^{\mathrm{a}}$, and Kunyan Sui a,*

a.State Key Laboratory of Bio-fibers and Eco-textiles, College of Materials Science and Engineering, Shandong Collaborative Innovation Center of Marine Biobased Fibers and Ecological Textiles, Institute of Marine Biobased Materials, Qingdao University, Qingdao 266071, P.R.China

b.Key Laboratory of Science \& Technology of Eco-Textile, Ministry of Education College of Chemistry, Chemical Engineering and Biotechnology Centre for Advanced Low Dimension Materials Donghua University Shanghai, 201620, P. R. China

${ }^{1}$. These authors contributed equally to this work.

*Corresponding author. E-mail address: fanwenxin@qdu.edu.cn; sky@qdu.edu.cn

\section{Section S1. Characterization of dual-gradient GO/PAMAEMA hydrogel actuators}

Two hydrogel samples used for CLSM imaging were respectively immersed and stained by a dilute solution of sodium fluorescein (green fluorescence) and Rhodamine 6G (red fluorescence). Negatively charged sodium fluorescein would preferentially bind to positively charged PDMAEMA through electrostatic interaction, while Rhodamine $6 \mathrm{G}$ molecules would bind to GOs due to $\pi-\pi$ stacking. The uniformly distributed red fluorescence suggests that the GOs distribute uniformly along the gel thickness, and the gradient green fluorescence indicated the gradient structure of PDMAEMA networks (Fig. 2d). The observation of denser PDMAEMA at HD side than LD side is in agreement with the SEM images (Fig. 2c and d). Besides, XPS was used to detect the crosslinking density of the hydrogel actuator. The similar nitrogen content between the HD and LD sides indicates a similar crosslinking degree for the two sides (Fig. S2). Considering a much higher chain density of PDMAEMA at HD side than LD side, it can be inferred that the HD side has a higher crosslinking density (i.e., number of crosslinking bonds per volume) than the LD side. 


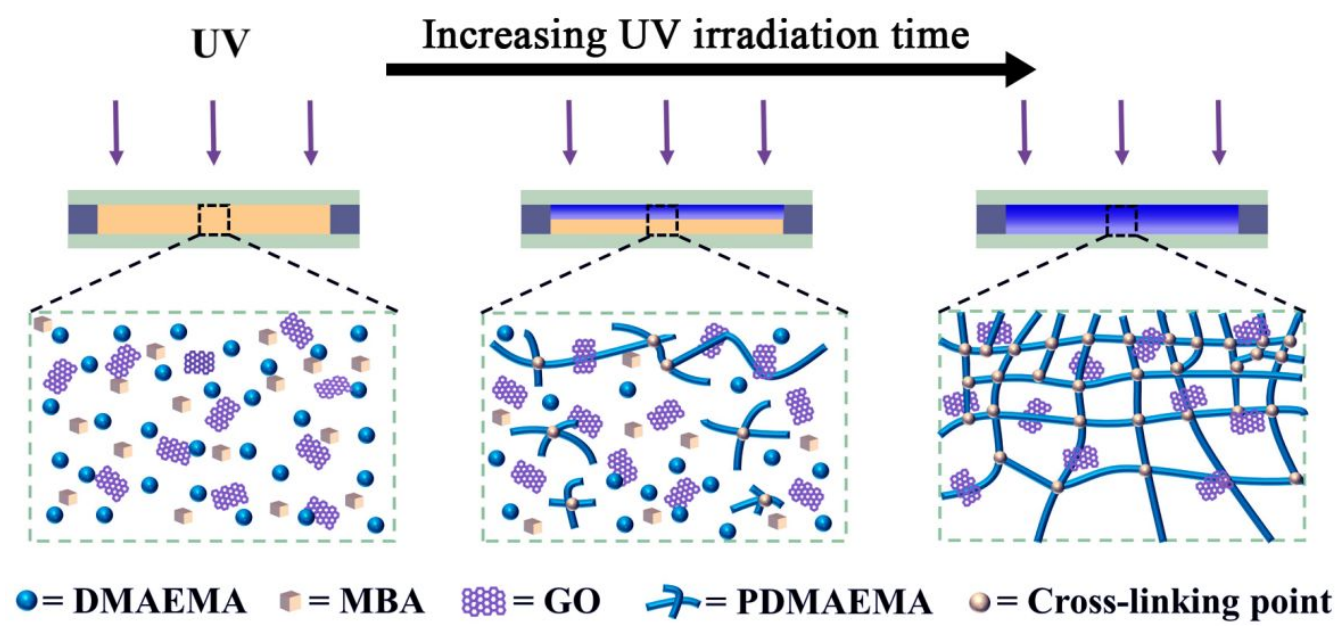

Fig1. S1. Schematic illustration of the fabrication of the GO/PDMAEMA dual-gradient hydrogel actuators.
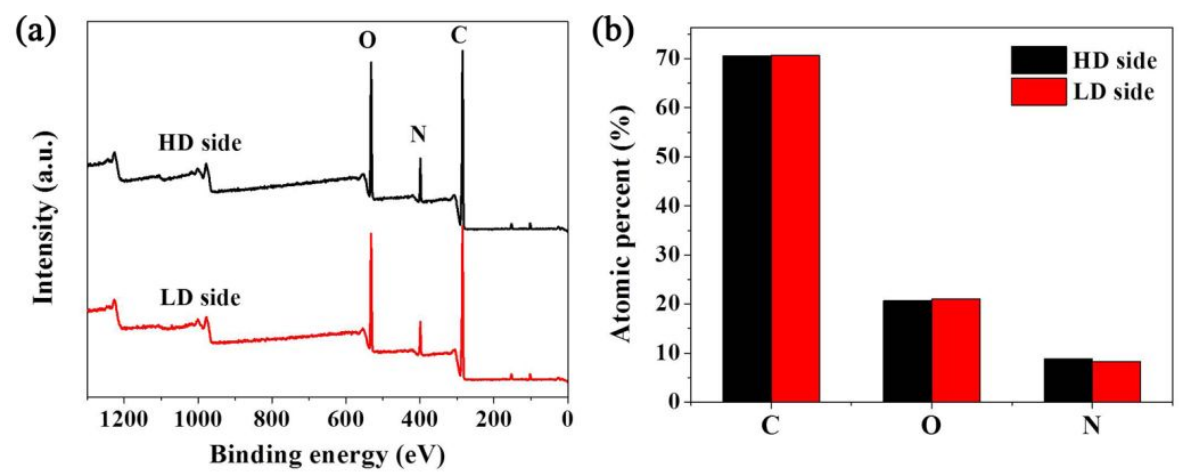

Fig. S2. (a) XPS survey spectra and (b) atomic percent of carbon, nitrogen and oxygen for the HD and LD sides of dual-gradient hydrogel actuator.

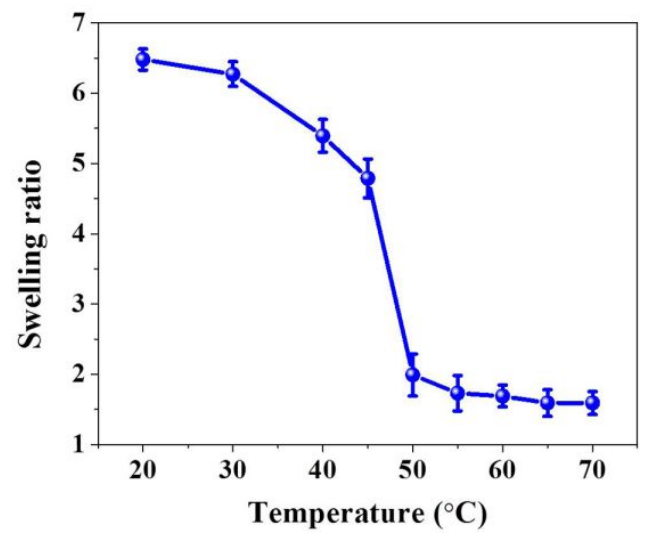

Fig. S3. Dependence of the swelling ratio of the dual-gradient hydrogel actuators on the pre-deformation temperature. The swelling ratio was calculated as $S R=W_{S} / W_{d}$, where $W_{S}$ and $W_{d}$ are the weight of the swollen hydrogel actuator and corresponding dried one, respectively. 


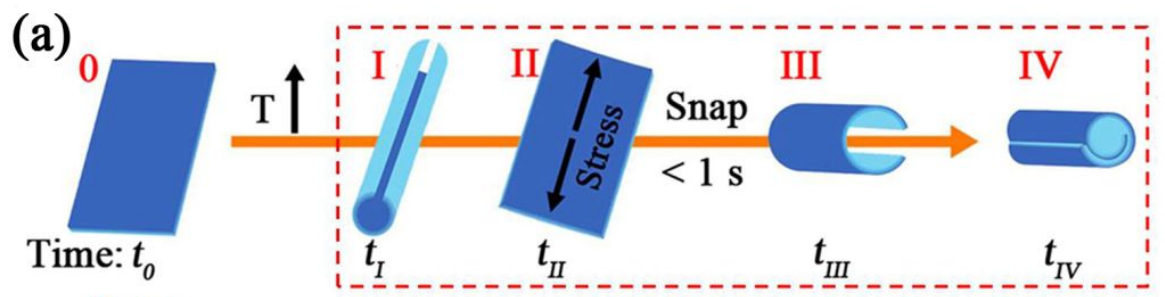

$20^{\circ} \mathrm{C}$

High temperature
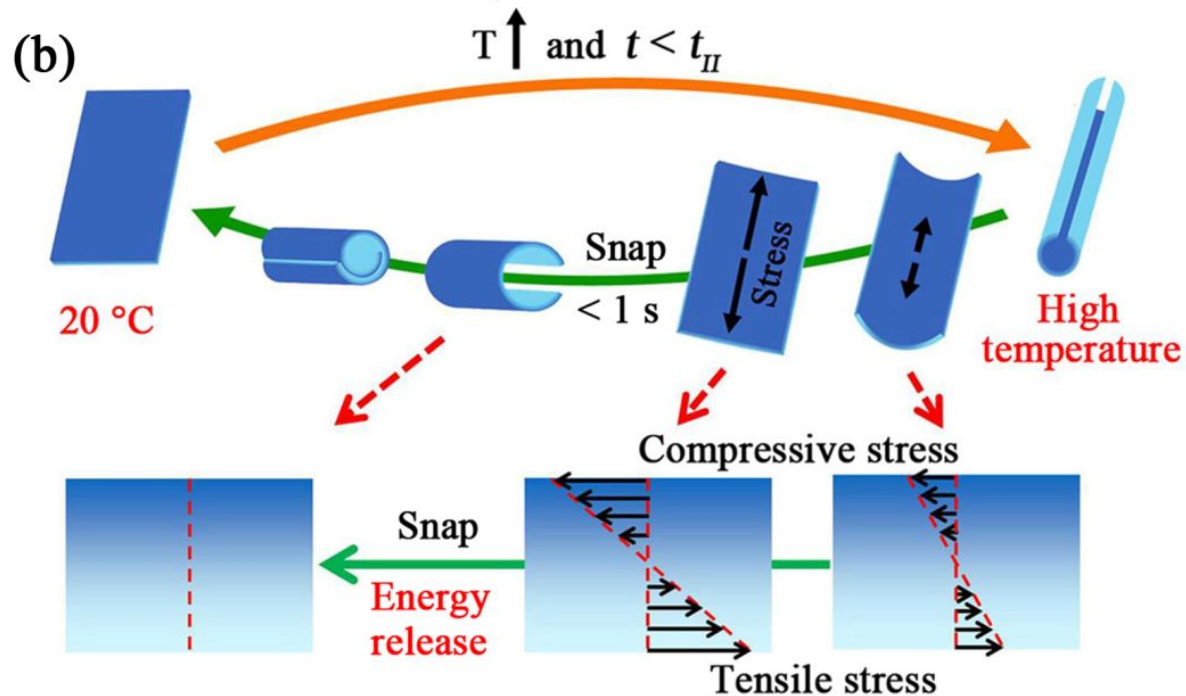

Fig. S4. (a) Schematic illustration of the shape transformation of dual-gradient hydrogel actuator upon the trigger of high temperature. (b) Schematic illustration of the shape transformation of dual-gradient hydrogel actuator in low-temperature water after pre-deformation in high-temperature water.

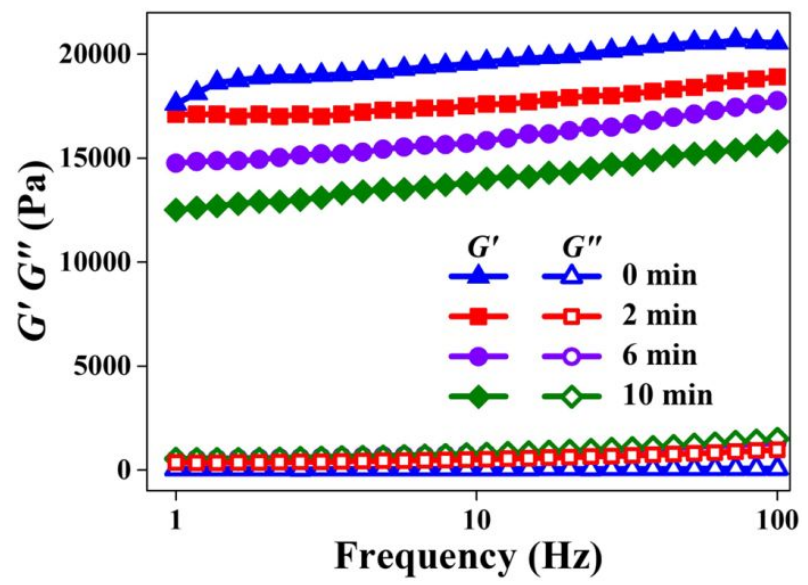

Fig. S5. Storage modulus $\left(G^{\prime}\right)$ and loss modulus $\left(G^{\prime \prime}\right)$ versus angular frequency curves of the hydrogel actuators after predeformation at $65^{\circ} \mathrm{C}$ for different times. 


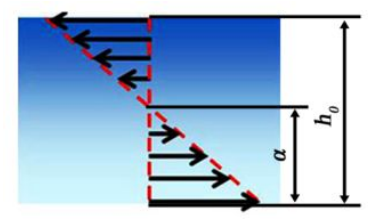

Fig. S6. Schematic illustration of the stress distribution of dual-gradient hydrogel actuators at the moment of snapping deformation.

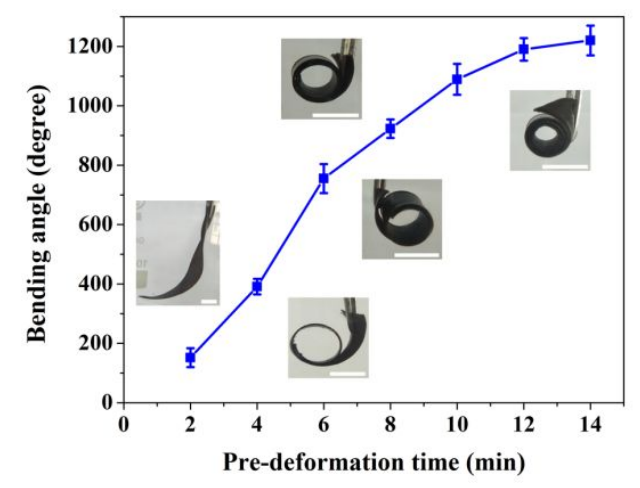

Fig. S7. Maximum bending angle of the snapping deformation for the hydrogel actuators after pre-deformation at $60{ }^{\circ} \mathrm{C}$ for different times. Scale bars, $1 \mathrm{~cm}$.

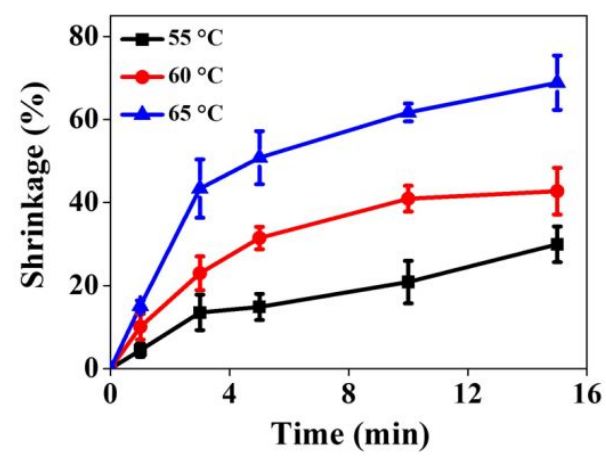

Fig. S8. Deswelling ratio of the hydrogel actuators at different temperatures as a function of immersing time. 

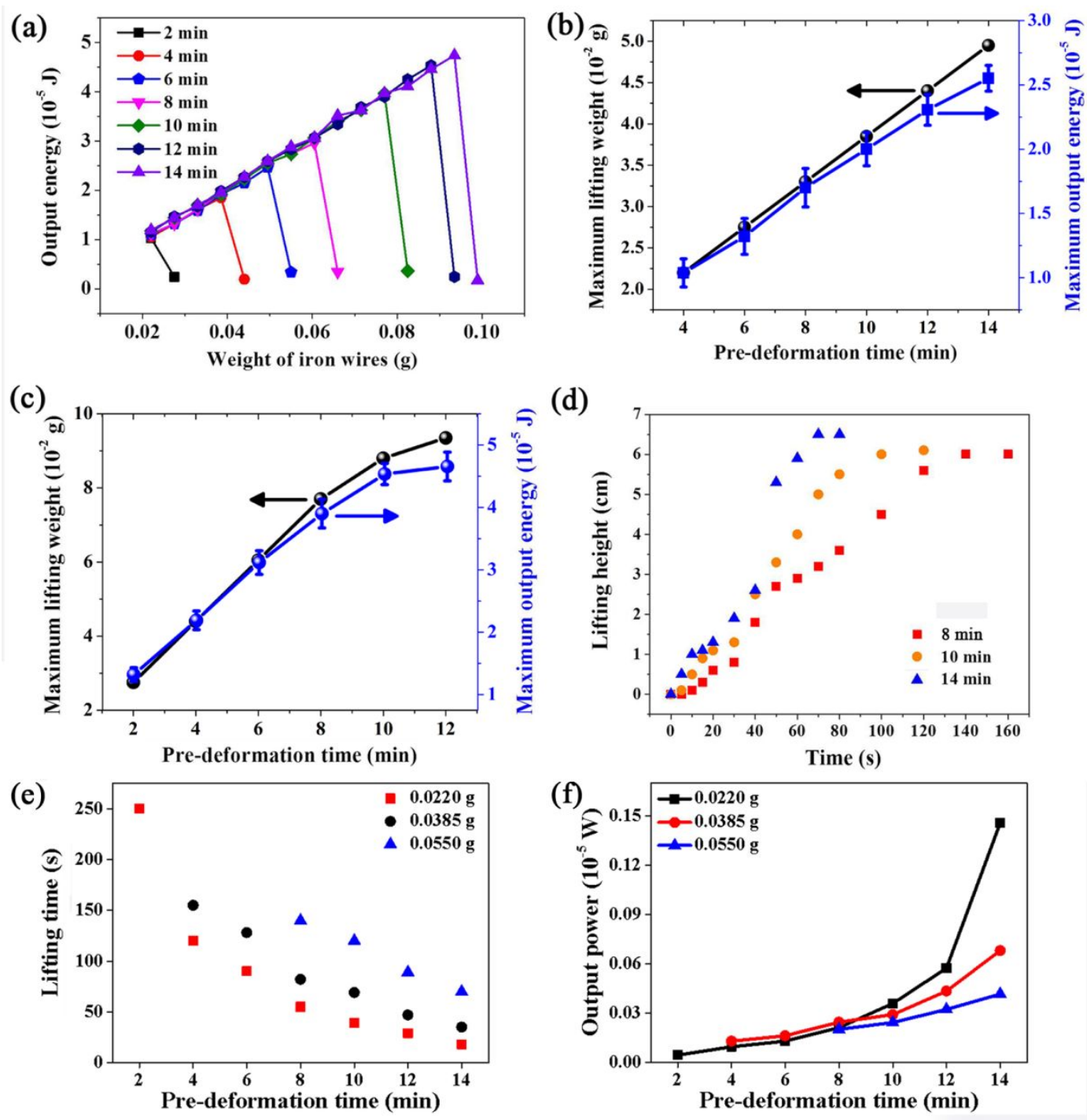

Fig. S9. a) Output energy at $20{ }^{\circ} \mathrm{C}$ by the hydrogel actuators after pre-deformation at $65{ }^{\circ} \mathrm{C}$ for different times. $\mathrm{b}$ and c) Maximum lifting weight and output energy at $20^{\circ} \mathrm{C}$ by the hydrogel actuators after pre-deformation at (b) $60{ }^{\circ} \mathrm{C}$ and (c) $70{ }^{\circ} \mathrm{C}$ for different times. d) Height of lifting $0.055-\mathrm{g}$ object at $20^{\circ} \mathrm{C}$ by the hydrogel actuators after pre-deformation at $65{ }^{\circ} \mathrm{C}$ for different times as a function of lifting time. (e and f) Dependence of the (e) lifting time and (f) output power of hydrogel actuators on the predeformation time at $65{ }^{\circ} \mathrm{C}$ and the weight of iron wires. Here the output power is defined as ratio of output energy to lifting time. 


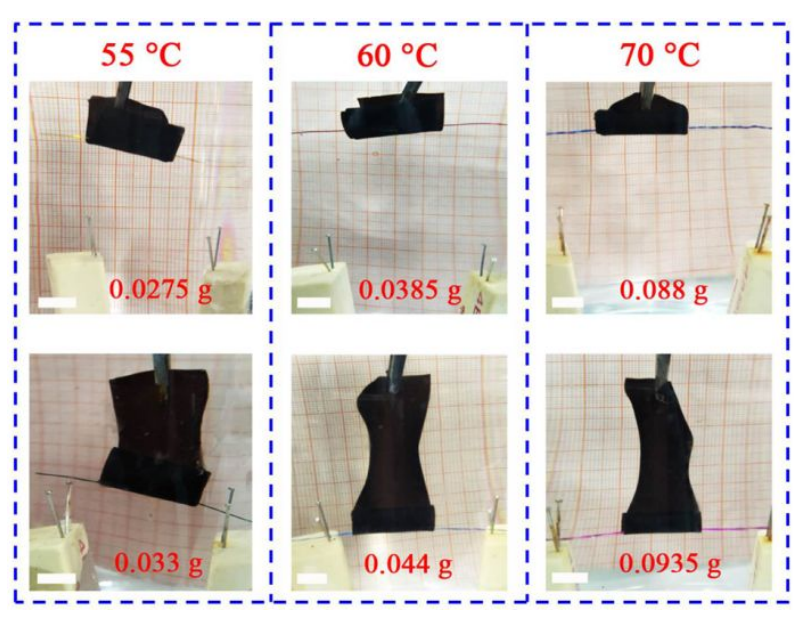

Fig. S10. Optical images show the weight lifting of dual-gradient actuators after pre-deformation at different temperature for $10 \mathrm{~min}$. Scale bars, $1 \mathrm{~cm}$.
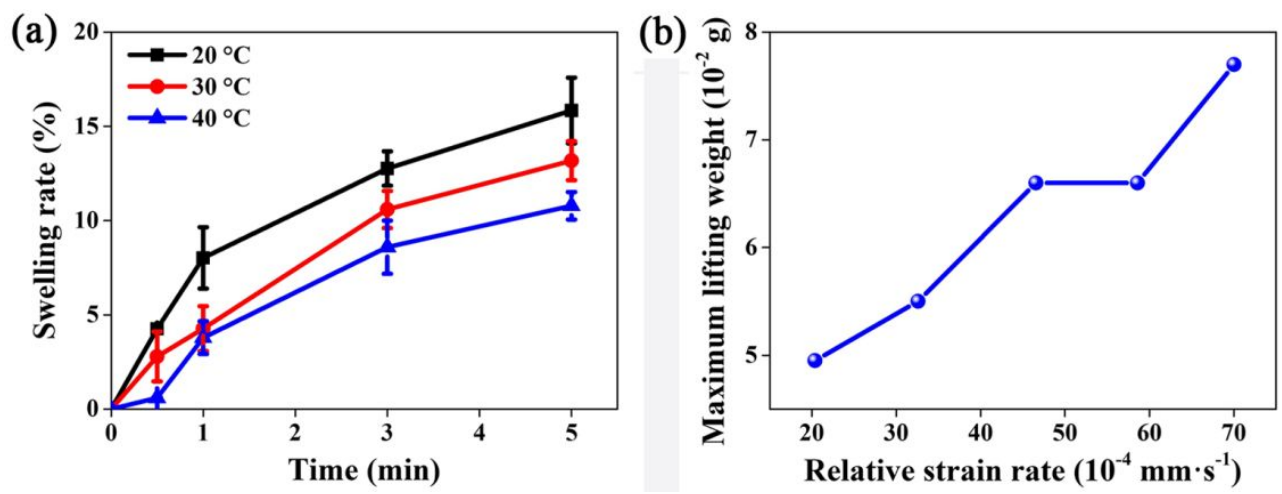

Fig. S11. (a) Relative swelling ratio of the hydrogel actuators at different operating temperature as a function of operating time. The swelling rate is calculated by $S R=$ $\left(W_{s}-W_{0}\right) / W_{0}$, where $W_{0}$ and $W_{s}$ are weight of predeformed hydrogel actuators before and after swelling at low temperatures, respectively. (b) Maximum lighting weights of hydrogel actuators as a function of relative strain rate. 

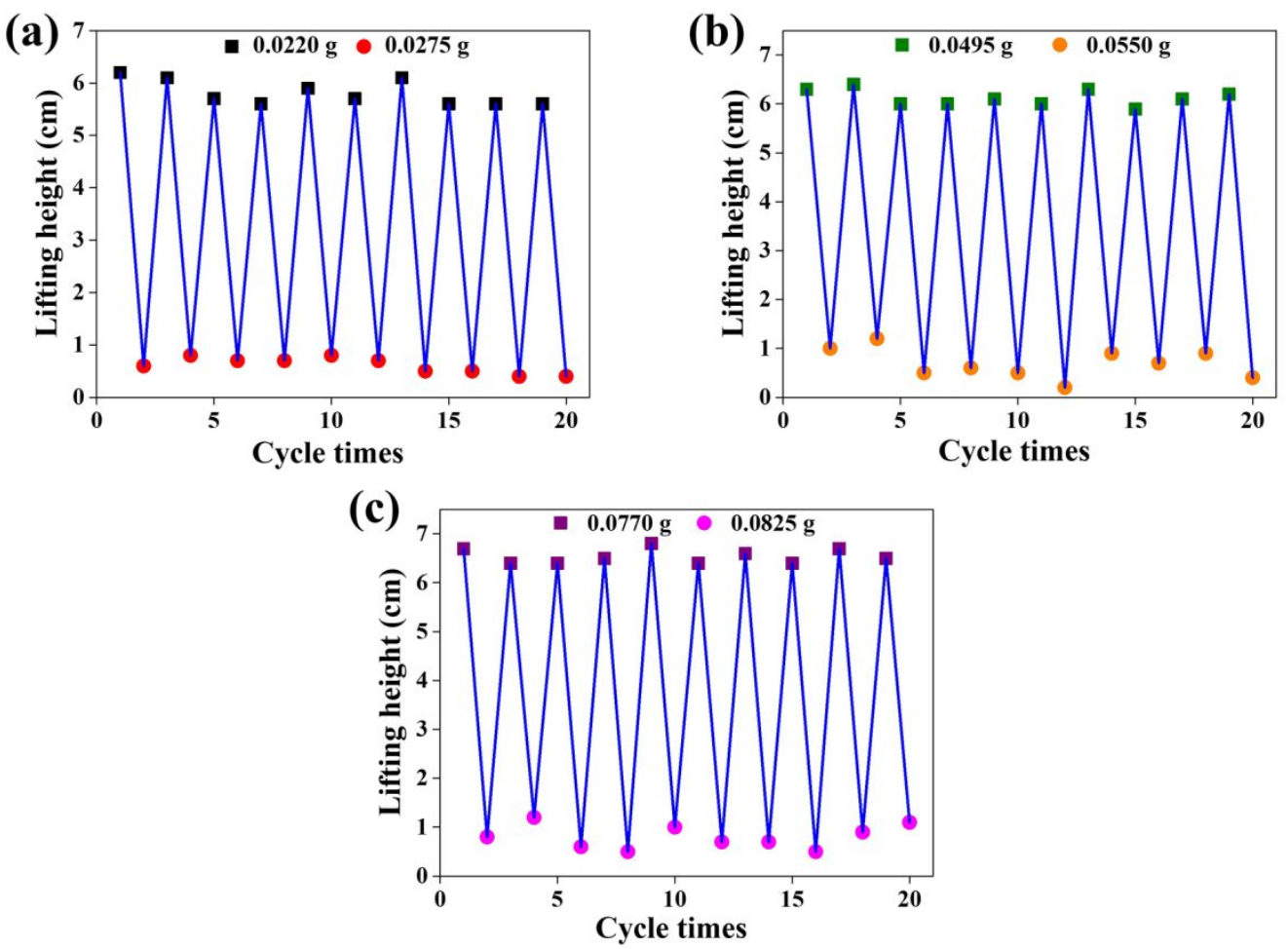

Fig. S12. Lifting height of iron wires with different weights by the hydrogel actuators after predeformation at $65{ }^{\circ} \mathrm{C}$ for (a) $2 \mathrm{~min}$, (b) 6 min and (c) $16 \mathrm{~min}$. The maximum lifting weight is constant after 20 cycles of weight lifting for the hydrogel actuators pretreated at the same condition.

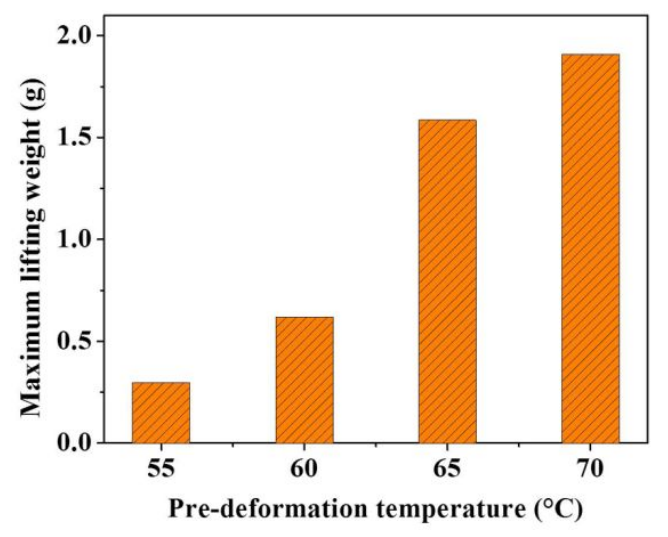

Fig. S13. Maximum lifting weight at $20{ }^{\circ} \mathrm{C}$ by the hydrogel actuators after pre-deformation at different temperatures for $10 \mathrm{~min}$. 


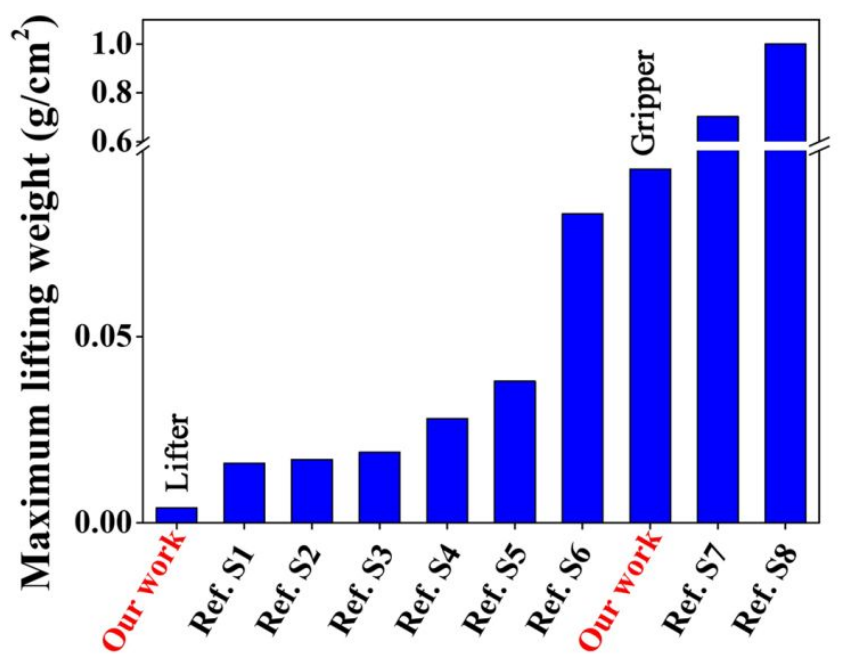

Fig. S14. Comparison on the maximum lifting weight of typical hydrogel-based actuators.

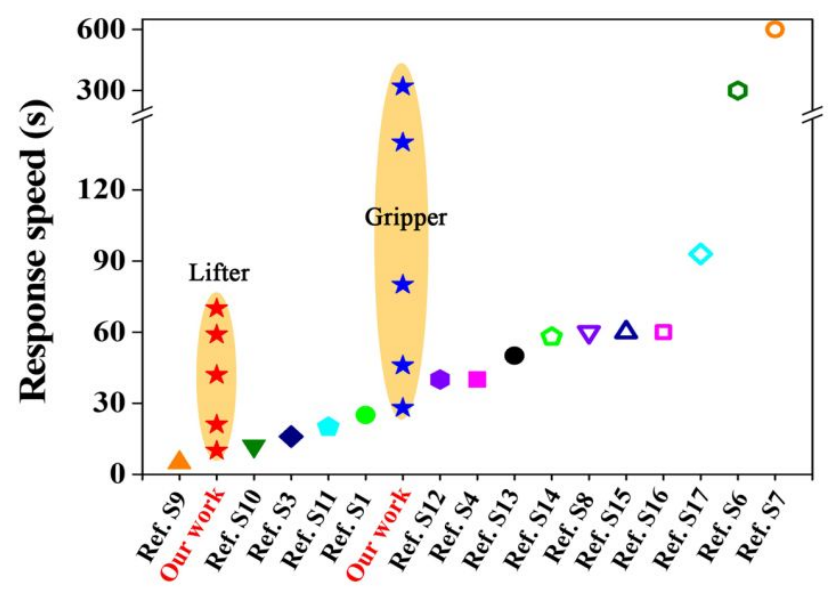

Fig. S15. Comparison on the actuation speed of typical hydrogel-based actuators. 

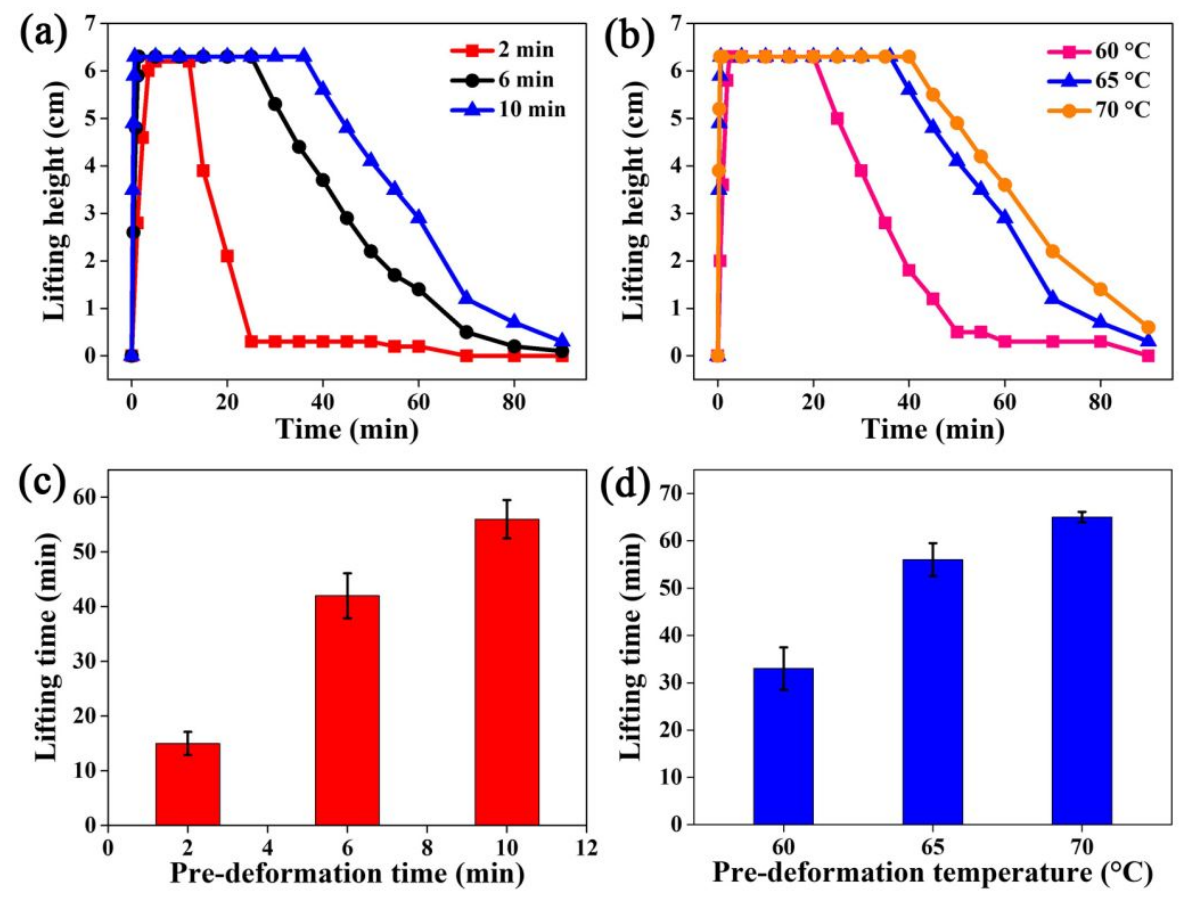

Fig. S16. ( $\mathrm{a}$ and $\mathrm{b}$ ) Lifting height of $0.022 \mathrm{~g}$ iron wire by the hydrogel actuators as a function of lifting time. Before the weight lifting, the hydrogel actuators were pretreated under different pre-deformation conditions: (a) at $65^{\circ} \mathrm{C}$ for different times and (b) at different temperatures for $10 \mathrm{~min}$. (c and d) Dependence of weight holding time of the hydrogel actuators on (c) pre-deformation time and (d) pre-deformation temperature. Here the weight holding time is defined as the lasting time that the lifting height of iron wires is higher than half of maximum lifting height.

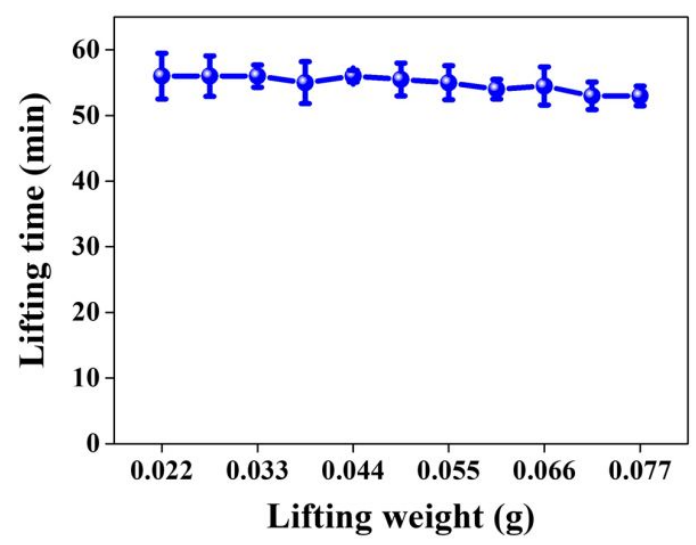

Fig. S17. Weight holding time of the hydrogel actuators as a function of the weight of iron wires. Before the weight lifting, the hydrogel actuators were pretreated at $65{ }^{\circ} \mathrm{C}$ for $10 \mathrm{~min}$. 


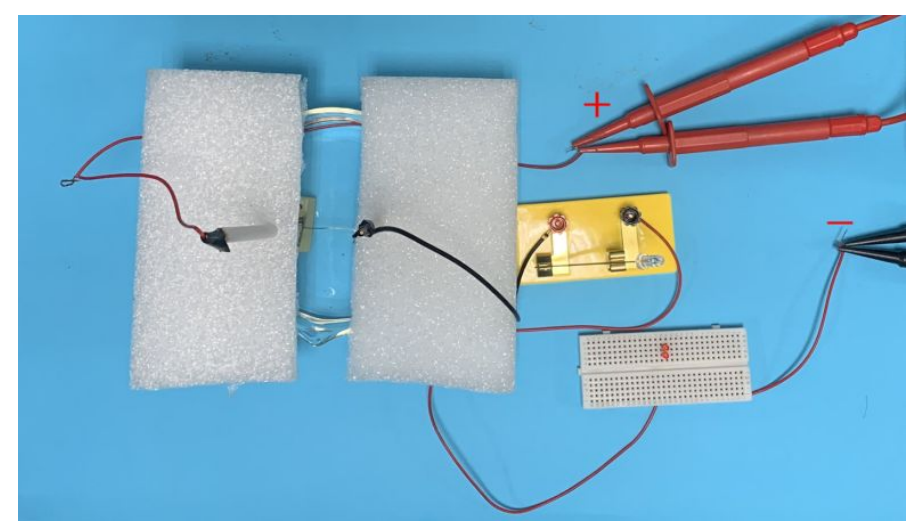

Fig. S18. Photograph of the smart switch circuit in cold water.

\section{Supporting movie}

Movie S1. Shape transformation of the hydrogel actuator in $65^{\circ} \mathrm{C}$ water.

Movie S2. Snapping deformation of the hydrogel actuator in $20{ }^{\circ} \mathrm{C}$ water after pre-deformation at $65^{\circ} \mathrm{C}$ for $10 \mathrm{~min}$.

Movie S3. Lifting of $0.0495-\mathrm{g}$ iron wire at in $20{ }^{\circ} \mathrm{C}$ water by the hydrogel actuator after pre-deformation at $65^{\circ} \mathrm{C}$ for $6 \mathrm{~min}$.

Movie S4. Lifting of $0.055-\mathrm{g}$ iron wire at in $20{ }^{\circ} \mathrm{C}$ water by the hydrogel actuator after pre-deformation at $65^{\circ} \mathrm{C}$ for $6 \mathrm{~min}$.

Movie S5. Lifting of $0.055-\mathrm{g}$ iron wire at in $20{ }^{\circ} \mathrm{C}$ water by the hydrogel actuator after pre-deformation at $65^{\circ} \mathrm{C}$ for $8 \mathrm{~min}$.

Movie S6. Lifting of $0.055-\mathrm{g}$ iron wire at in $20{ }^{\circ} \mathrm{C}$ water by the hydrogel actuator after pre-deformation at $65^{\circ} \mathrm{C}$ for $14 \mathrm{~min}$.

Movie S7. Lifting of 1.9 -g object at in $20^{\circ} \mathrm{C}$ water by the T-shaped hydrogel actuator after pre-deformation at $65^{\circ} \mathrm{C}$ for $12 \mathrm{~min}$.

Movie S7. Lifting of 1.9-g object at in $20^{\circ} \mathrm{C}$ water by the T-shaped hydrogel actuator after pre-deformation at $65^{\circ} \mathrm{C}$ for $10 \mathrm{~min}$.

\section{References}

(S1) Lin, D.; Ma, M. S.; Xu, J. K.; Si, C. L.; Wang, X. H.; Liu, Z.; Ni, Y. H. All-Lignin-Based Hydrogel with Fast pH-Stimuli Responsiveness for Mechanical Switching and Actuation. Chem. Mater. 2020, 32, 4324-4330. 
(S2) Zheng, W. J.; An, N.; Yang, J. H.; Zhou, J. X.; Chen, Y. M. Tough Al-alginate/Poly(N-isopropylacrylamide) Hydrogel with Tunable LCST for Soft Robotics. ACS Appl. Mater. Interfaces 2015, 7, 1758-1764.

(S3) Dong, Y.; Wang, J.; Guo, X. K.; Yang, S. S.; Ozen, M. O.; Chen, P.; Liu, X.; Du, W.; Xiao, F.; Demirci, U.; Liu, B. F. Multi-stimuli-responsive Programmable Biomimetic Actuator. Nat. Commun. 2019, 10, 4087.

(S4) Palleau, E.; Morales, D.; Dickey, M. D.; Velev, O. D. Reversible Patterning and Actuation of Hydrogels by Electrically Assisted Ionoprinting. Nat. Commun. 2013, 4, 2257.

(S5) Lu, D.; Zhu, M.; Wu, S.; Lian, Q.; Wang, W.; Adlam, D.; Hoyland, J. A.Saunders, B. R. Programmed Multiresponsive Hydrogel Assemblies with Light-Tunable Mechanical Properties, Actuation, and Fluorescence. Adv. Funct. Mater. 2020, 30, 1909359.

(S6) Zheng, J.; Xiao, P.; Le, X. X.; Lu, W.; Théato, P.; Ma, C. X.; Du, B. Y.; Zhang, J. W.; Huang, Y. J.; Chen, T. Mimosa Inspired Bilayer Hydrogel Actuator Functioning in Multi-environments. J. Mater. Chem. C 2018, 6, 1320-1327.

(S7) Han, D.; Farino, C.; Yang, C.; Scott, T.; Browe, D.; Choi, W.; Freeman, J. W.; Lee, H. Soft Robotic Manipulation and Locomotion with a 3D Printed Electroactive Hydrogel. ACS Appl. Mater. Interfaces 2018, 10, 17512-17518..

(S8) Yang, C.; Liu, Z.; Chen, C.; Shi, K.; Zhang, L.; Ju, X. J.; Wang, W.; Xie, R.; Chu, L. Y. Reduced Graphene Oxide-Containing Smart Hydrogels with Excellent Electro-Response and Mechanical Properties for Soft Actuators. ACS Appl. Mater. Interfaces 2017, 9, 15758-15767.

(S9) Song, Y.; Liu, Y.; Jiang, H.; Xue, J.; Yu, Z. P.; Li, S. Y.; Han, Z. W.; Ren, L. Q. Janus Soft Actuators with On-Off Switchable Behaviors for Controllable Manipulation Driven by Oil. ACS Appl. Mater. Interfaces 2019, 11, 13742-13751.

(S10) Xiao, S.; Zhang, M.; He, X.; Huang, L.; Zhang, Y.; Ren, B.; Zhong, M.; Chang, Y.; Yang, J.; Zheng, J. Dual Salt- and Thermoresponsive Programmable Bilayer Hydrogel Actuators with Pseudo-Interpenetrating Double-Network Structures. ACS Appl. Mater. Interfaces 2018, 10, 21642-21653. 
(S11) Mo, K. W.; He, M.; Cao, X. D.; Chang, C. Y. Direct Current Electric Field Induced Gradient Hydrogel Actuators with Rapid Thermo-responsive Performance as Soft Manipulators. J. Mater. Chem. C 2020, 8, 2756-2763.

(S12) Zhang, X.; Xu, X. L.; Chen, L. S.; Zhang, C.; Liao, L. Q. Multi-responsive Hydrogel Actuator with Photo-switchable Color Changing Behaviors. Dyes and Pigments 2020, 174, 108042.

(S13) Ma, C. X.; Le, X. X.; Tang, X. L.; He, J.; Xiao, P.; Zheng, J.; Xiao, H.; Lu, W.; Zhang, J. W.; Huang, Y. J.; Chen, T. A Multiresponsive Anisotropic Hydrogel with Macroscopic 3D Complex Deformations. Adv. Funct. Mater. 2016, 26, 8670-8676.

(S14) Yao, C.; Liu, Z.; Yang, C.; Wang, W.; Ju, X. J.; Xie, R.; Chu, L. Y. Smart Hydrogels with Inhomogeneous Structures Assembled Using Nanoclay-Cross-Linked Hydrogel Subunits as Building Blocks. ACS Appl. Mater. Interfaces 2016, 8, 21721-21730.

(S15) Xu, Z. X.; Fu, J. Programmable and Reversible 3D-/4D-Shape-Morphing Hydrogels with Precisely Defined Ion Coordination. ACS Appl. Mater. Interfaces 2020, 12, 26476-26484.

(S16) Yang, Y.; Tan, Y.; Wang, X. L.; An, W. L.; Xu, S. M.; Liao, W.; Wang, Y. Z. Photothermal Nanocomposite Hydrogel Actuator with Electric-Field-Induced Gradient and Oriented Structure. ACS Appl. Mater. Interfaces 2018, 10, 7688-7692.

(S17) Yao, C.; Liu, Z.; Yang, C.; Wang, W.; Ju, X. J.; Xie, R.; Chu, L. Y. Poly(N-isopropylacrylamide)-Clay Nanocomposite Hydrogels with Responsive Bending Property as Temperature-Controlled Manipulators. Adv. Funct. Mater. 2015, 25, 2980-2991. 